\title{
Therapeutic activity of sulphadimethoxine and Bifuran against $E$. tenella and effect of medication on the development of immunity
}

\author{
by J. SINGH and O. HUSSAIN \\ Assam Agricultural University, Khanapara, Gauhati-22, Assam, India.
}

\section{Summary.}

Therapeutic activity of sulphadimethoxine and Bifuran in drinking water against different levels of infection $(5,000,10,000,25,000$ and 50,000 oocysts per chick) with Eimeria tenella and effect of medication on development of immunity was assessed.

Medication was started after 96 hours of the infection. Sulphadimethoxine gave better control (performance indices: 234, 193, 155 and 112, respectively) than Bifuran (performance irdices: 194, 129, 74 and 40, respectively) against all levels of the infection tested. Effectiveness of both the drugs decreased with increasing levels of the infection. Both the drugs interfered in the development of immunity which was inversely proportionate to the level of infection. Interference in development of immunity was more with sulphadimethoxine but these chicks were still solidly immune to the challenge infection.

\section{Résuméé}

Activité thérapeutique de la sulfadiméthoxine et du Bifuran contre Eimeria tenella et effet du traitement sur le développement de l'immunité chez le Poussin.

L'activité thérapeutique de la sulfadiméthoxine et du Bifuran chez le Poussin pour une eau potable à différents taux d'infection par Eimeria tenella $(5000,10000,25000$, 50000 oocystes par Poussin), et l'effet du traitement sur le développement de l'immunité ont été testés.

Le traitement a été entrepris 96 jours après l'infestation. Aux différents taux d'infestation étudiés, la sulfadiméthoxine a donné des résultats supérieurs (index de performance : 234, 193, 155, 112, respectivement) au Bifuran (*) (index de performance: 194, 129, 74, 40 , respectivement).

(*) Bifuran tablets manufactured by $\mathrm{M} / \mathrm{S}$ Smith, Kline and French, Bangalore. Each tablet contains $100 \mathrm{mg}$ of nitrofurazone and $14.5 \mathrm{mg}$ of furazolidone.

Reçu le 15 janvier 1977. 
L'efficacité des deux produits décroît lorsque les taux d'infection augmentent. Les deux produits interfèrent dans le développement de l'immunité qui est inversement proportionnel au taux de l'infestation. Cette interférence est plus marquée avec la sulfadiméthoxine ; néanmoins, les poussins sont encore solidement protégés contre une infestation ultérieure.

Sulphadimethoxine was reported by Tsunoda (1963), to be the most effective among thirteen sulphonamides against resistant-strains of E. tenella. Mitrovic and Bauernfeind (1967) confirmed this finding and reported that the drug did not interfere in the development of immunity. They recommended the use of 0.05 per cent of the drug in drinking water from 3rd day of the infection and for six consecutive days. Since, strains of coccidia isolated from different localities often very in their susceptibility to drugs (Ball, 1966; Joyner, 1970; Ryley and Betts, 1973), therefore, the activity of even a tested compound needs to be verified against local strains. Therapeutic activity of sulphadimethoxine against various levels of an indigenous strain of $E$. tenella infection, simulating infections in nature, and effect of medication on the development of immunity was investigated and compared with that of Bifuran. Results are communicated in this paper.

\section{Materials and methods}

Parasite: Single-line strain of E. tenella was isolated from a chick died of caecal coccidiosis at the Government Poultry Farm, Khanapara, Assam. The culture was further multiplied by serial passage in chicks reared coccidia-free from the time of their hatching.

Experimental chicks: Day-old, White-Leghorn, unsexed chicks were procurred from Government Hatchery, Khanapara, and reared coccidia free up to one week of their age when utilized in the experiments.

Medication: Sulphadimethoxine (as 0.05 per cent) and Bifuran (one tablet dissolved in one litre of water) were given in drinking water. Medication was started on 96th hour of infection and continued for 6 and 7 days, respectively. During the test period only medicated water was given. The levels of infection used were $5,000,10,000,25,000$ and 50,000 sporulated oocysts per chick given as single inoculum.

Experimental design: Twenty chicks were employed in each group except uninfected-medicated and uninfected-unmedicated controls which had 10 chicks per group. Chicks in each group were infected individually with the same number of sporulated oocysts. Half the number of infected chicks in each group was killed by cervical dislocation, caeca taken out and lesions scored according to the technique developed by Johnson and Reid (1970). 
Weight of the chicks was recorded on Day 0,6 and 14 of the initial infection and on 6th day of the challenge infection. Weight gains were expressed as percent of the weight gain of uninfected-unmedicated chicks.

Faeces of each group were collected separately from 7 th to 14 th day and oocysts counted daily.

On Day 14, the survivors were challenged with 100,000 oocysts per chick. Half of the survivors were killed on Day 6 of the challenge infection, caeca taken out and lesions scored. Faeces of the remaining chicks were collected from 7 th to 9th day of the challenge and oocysts counted.

On Day 9 survivors were slaughtered, oocysts harvested from the caeca and suspended in water. Oocysts in the suspension were counted.

The criteria kept in view for evaluating the efficacy of the drug on initial infection were: growth rate, mortality, faecal score $=$ clubbed together and expressed as performance index (Morehouse and Baron, 1970), lesion score, oocyst production and immunity index (Singh and Gill, 1976). Immunity index was obtained by totalling per cent growth rate, per cent survival, per cent protection against lesions and per cent protection against oocyst production after the challenge infection. From immunity index, per cent interference in the development of immunity (Singh and Gill, 1976) was calculated.

\section{Results}

Data on the activity of Bifuran and sulphadimethoxine against different doses of E. tenella are summarized in table $I$, on oocyst production in table $I I$ and effect of medication on the development of immunity in table III.

It was observed that untreated infection with 5,000 oocysts resulted in 25 per cent mortality. The rate of mortality, lesions and oocyst production increased with the increasing doses of infection such that no chick survived of the infection with 50,000 oocysts per chick. Medication afforded partial protection which decreased with the increase in infection level. However, the medicated chicks had mild lesions, produced lesser number of oocysts and showed higher weight gains as compared with infected-unmedicated controls. The drug was quite effective in retaining the normalcy of the faeces whereas the untreated chicks passed ample amount of blood in faeces (see tables I and II).

The medication caused interference in the development of immunity which was inversely proportionate to the degree of infection. Thus infected and treated chicks were still solidly immune to the challenge infection as no mortality occurred in them. Nevertheless, the chicks initially infected with 5,000 or 10,000 oocysts per chick developed mild lesions and produced oocysts but frank bleeding was not observed as seen in freshly infected group (see table III). 


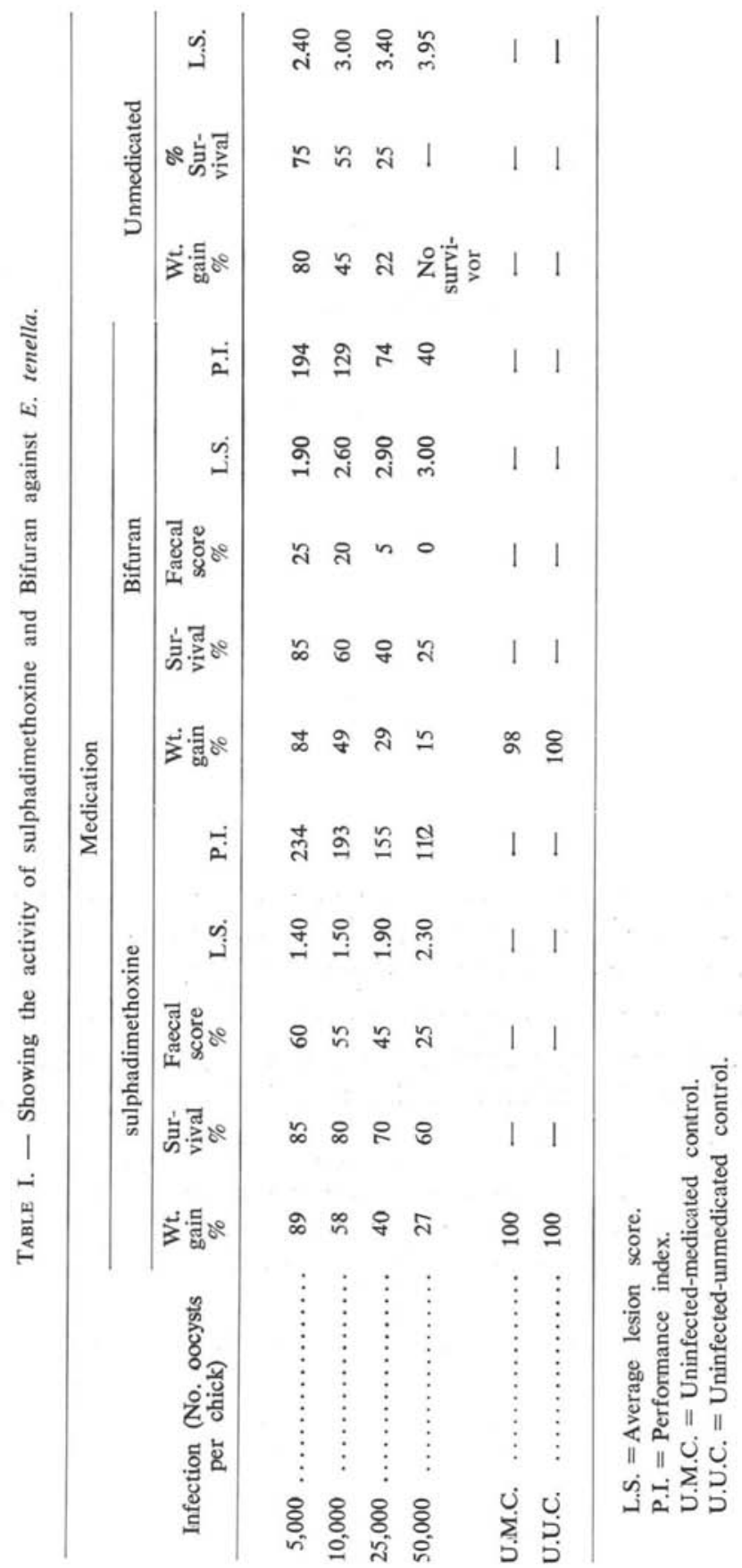


TABLE II. - Showing total oocyst production from 7th to 14 th day of initial infection (E. tenella) and from 7 th to 9 th day of challenge infection.

\begin{tabular}{|c|c|c|c|c|c|}
\hline \multirow{3}{*}{ Infection } & \multirow{3}{*}{$\begin{array}{l}\text { Group } \\
\text { of } \\
\text { chicks }\end{array}$} & \multicolumn{4}{|c|}{ Oocysts produced (Million/chick) } \\
\hline & & \multicolumn{4}{|c|}{ Group initially infected with (No. oocyst/chick } \\
\hline & & 5,000 & 10,000 & 25,000 & 50,000 \\
\hline Initial .. & $\begin{array}{l}\text { Treated with: } \\
\text { sulphadimethoxine } \quad \ldots \ldots \\
\text { Bifuran } \ldots \ldots \ldots \ldots \cdots \cdots \\
\text { Untreated } \quad \ldots \ldots \ldots \ldots \cdots\end{array}$ & $\begin{array}{r}7.15 \\
18.20 \\
35.90\end{array}$ & $\begin{array}{r}9.85 \\
19.80 \\
38.00\end{array}$ & $\begin{array}{l}10.70 \\
18.98 \\
36.06\end{array}$ & $\begin{array}{c}12.90 \\
20.86 \\
\text { No } \\
\text { survivor }\end{array}$ \\
\hline Challenge $\ldots \ldots \ldots$. & $\begin{array}{l}\text { sulphadimethoxine } \ldots \ldots \\
\text { Bifuran } \ldots \ldots \ldots \ldots \ldots \\
\text { Untreated } \ldots \ldots \ldots \ldots\end{array}$ & $\begin{array}{l}5.38 \\
2.80 \\
1.90\end{array}$ & $\begin{array}{l}3.00 \\
\text { Few } \\
\text { Nil }\end{array}$ & $\begin{array}{l}\text { Few } \\
\text { Nil } \\
\text { Nil }\end{array}$ & $\begin{array}{l}\text { Nil } \\
\text { Nil } \\
\text { No } \\
\text { survivor }\end{array}$ \\
\hline & Fresly infected $\ldots \ldots$. & 20.00 & - & - & - \\
\hline
\end{tabular}

TABLE III. - Showing the effect of challenge infection with 100,000 oocysts (E. tenella) in chicks which had recovered from initial infection. The last group comprised of the frehly infected controls.

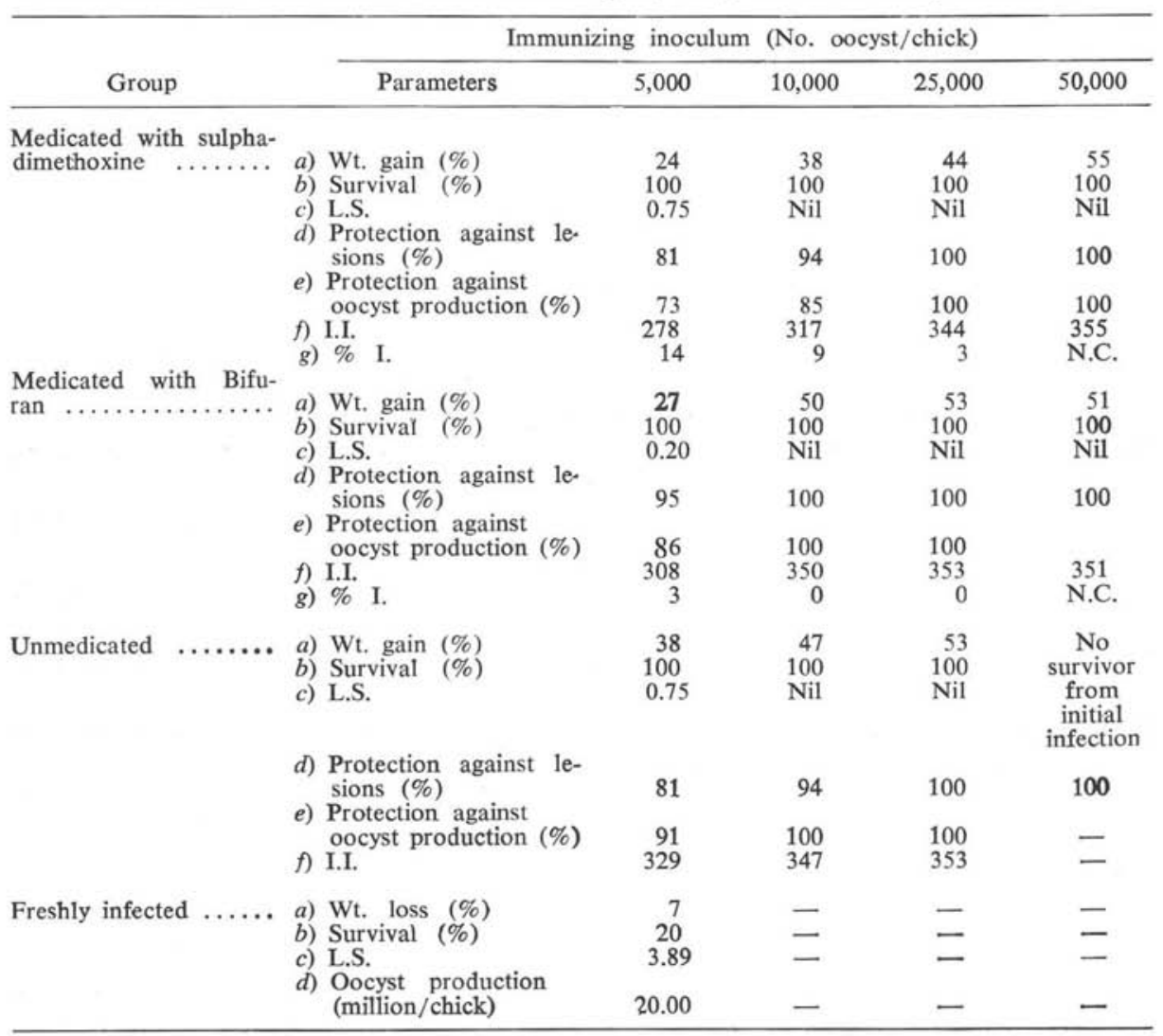

L.S. = Average lesion score (meximum lesion score 4.00). I.I. $=$ Immunity index. \% I. $=$ Per cent interference in development of immunity. N.C. = The $\%$ interference could not be calculated as all the chicks of unmedicated group died of the initial infection, hence, its immunity index required for calculating \% interference was not available. 


\section{Discussion}

The studies indicated that sulphadimethoxine proved superior than Bifuran in controlling all the levels of infection tested. The decrease in activity of Bifuran, as reported by the Farm Manager and evidenced by this investigation may possibly be due to the development of drug-ressistance of the parasite because Bifuran has been used at the farm for the last 5-6 years continuously. Such development of partial resistance to nitrofurans has been reported by Siegmann (1966). These studies also revealed that the organism was fully susceptible to sulphadimethoxine and the crossresistance between these two drugs in case of E. tenella can be ruled out. Hence, in a situation where this coccidium, resistance to Bifuran, appears to exist sulphadimethoxine can be safely substituted for this.

Further, sulphadimethoxine interfered in the development of immunity more than Bifuran but immunity in the chicks medicated with the former drug, was still sufficient to withstand the challenge. Therefore, sulphadimethoxine can be preferred over Bifuran for use in layers-in which immunity is essentially required and at the same time would cut sharply in the production of oocysts with a consequent reduction in the "build up" of infective material in the litter.

\section{ACKNOWLEDGMENT}

The authors are thankful to the Dean, College of Veterinary Science, Khanapara, Gauhati-22 for providing necessary facilities to carry out this work.

\section{References}

BALL (S. J.), 1966. - The response of different strains of E. acervulina and E. tenella to medication. Res. Vet. Sci., 7, 312-325.

JOHNSON (J.) et REID (W. M.), 1970. - Anticoccidial drugs: lesion scoring techniques in battery and floor-pen experiments with chicken. Exper. Parasitol., 28, 30-36.

JOYNER (L. P.), 1970. - Coccidiosis problems arising from the development of anticoccidial drug resistance. Exper. Parasitol., 28, 122-128.

Mitrovic (M.) et Bauernfeind (J. C.), 1967. - Sulphadimethoxine therapy of avian coccidiosis. Poultry Sci., 46, 402-411.

Morehouse (N. F.) et Baron (R. R.), 1970. - Coccidiosis : evaluation of Coccidiostats by mortality, weight gain and faecal scores. Exper. Parasitol., 28, 25-29.

RYLey (J. F.) et Betts (S. J.), 1973. - Chemotherapy of chicken coccidiosis. Adv. Pharmacol. Chemother., 11, 221-293.

Seigmann (O.), 1966. - Passage of an E. tenella strain in chicken treated with amprolium, glycarbylamide, nitrofurazone, or zoalene. Berl. Munch. Tierarztl. Wochenschr., 79, 268-271.

SiNGH (J.) et GILl (B. S.), 1976. - Activity of amprolium against different levels of Eimeria necatrix and effect of the medication on development of immunity. Rev. Parassitologia, 37, 63-70.

TSUNOJA (K.), 1963. - Drug-resistant chicken coccidia (Eimeria tenella) and experimental treatment of chickens infected with them. Bull. Nat. Inst. Animal Health (Japan), 3, 133-141. 